\title{
A new drug to treat prion diseases
}

Yamaguchi, K et al. Nat. Biomed. Eng. https://doi.org/10.1038/s41551-019-0349-8

Transmissible spongiform encephalopathies (TSEs) are rare, progressive neurodegenerative diseases characterized by the deposition of an aberrant conformational isoform $\left(\mathrm{PrP}^{\mathrm{Sc}}\right)$ of the normal cellular prion protein $\left(\mathrm{PrP}^{\mathrm{C}}\right)$ in the central nervous system. No treatment is currently available for these fatal conditions, but a new study brings hope by reporting the development of a drug that delays the progression of the disease in mice and macaques. "Prion disease is a zoonosis that affects humans and animals, including cows. In Europe, more than 100,000 cows have died from bovine spongiform encephalopathy (BSE) infection," says lead investigator Kazuo Kuwata, from Gifu University in Japan. "The development of an anti-prion drug would be beneficial not only for humans but also for animals," he adds.

The structure of $\mathrm{PrP}^{\mathrm{Sc}}$ and the mechanisms responsible for the pathological conversion of the prion protein remain elusive, which complicates the design of potential therapies against the pathogenic isoform. In addition, anti-prion agents against one prion strain might not be effective against another strain. To overcome these issues, Kuwata and his team decided to therapeutically target $\operatorname{PrP}^{\mathrm{C}}$, the normal prion isoform, which is universal among species. They hypothesized that a molecular chaperone that binds to $\operatorname{PrP}^{\mathrm{C}}$ to prevent its aberrant conformational change might efficiently treat the disease, independently of the TSE-causing agent.

The investigators used a program created in their lab called NAGARA to design a compound, MC, with high predicted affinity for $\operatorname{Pr}^{\mathrm{C}}$. They then assessed the ability of MC to influence $\operatorname{PrP}^{\mathrm{C}}$ conformation by in vitro conversion NMR. The technique, which allows realtime observation at the atomic level of the sonication-induced changes in $\mathrm{PrP}^{\mathrm{C}}$ conformation, confirmed that the binding of $\mathrm{MC}$ to $\mathrm{PrP}^{\mathrm{C}}$ could increase the stability of the protein.

In mice infected with the TSE strain Fukuoka-1, weekly intraperitoneal injection of MC increased survival time by about 3 weeks compared with saline treatment. The brain of infected mice treated with MC had smaller vacuolar area - a typical feature of the disease causing the brain to appear like a sponge - than the brain of mice treated with saline solution. In macaques, intravenous injection of MC slowed down the development of neurological and psychological symptoms caused by BSE infection and decreased the size of vacuolated areas and $\mathrm{PrP}^{\mathrm{Sc}}$ deposition in the brain compared with injection of saline solution.

Altogether these results confirm the efficacy of the compound with multiple strains and in multiple hosts. "Our next step is the planning of the first in-human clinical trial targeting patients with CreutzfeldtJakob disease," concludes Kuwata.

\section{Alexandra Le Bras}

Published online: 11 March 2019

https://doi.org/10.1038/s41684-019-0273-2

\section{InSTECH}

\section{Oral gavage, refined.}

Our plastic feeding needles have flexible tubes with

soft tips to reduce trauma, and they're disposable to

eliminate the hassle of cleaning.

Available in a range of sizes for mice, rats and other rodents. www.instechlabs.com
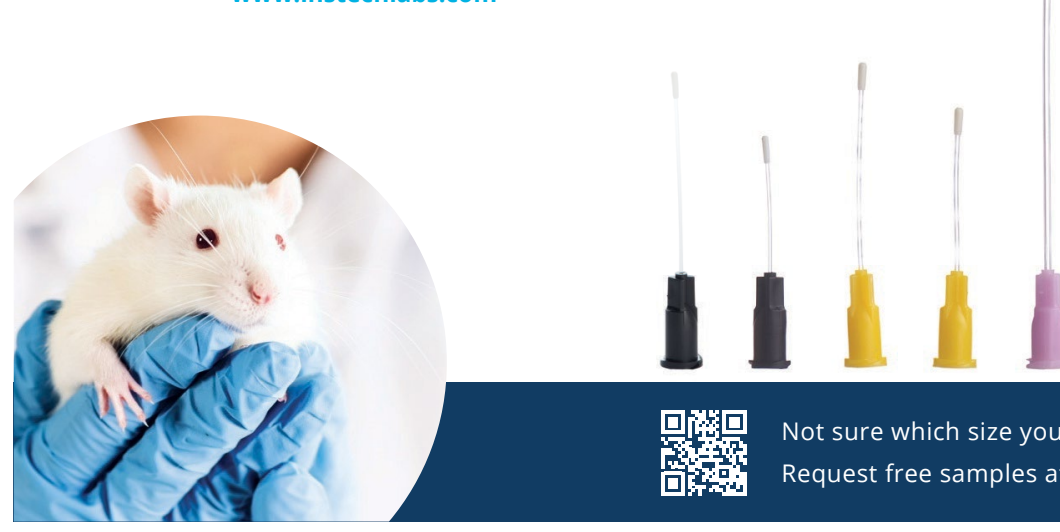